\title{
DESIGN OF SEISMIC RESISTANT PRESTRESSED CONCRETE STRUCTURES
}

\section{A. L. Andrews*}

\section{INTRODUCTION}

Companion papers deal with the recently introduced New Zealand Loadings Code(1) and with research into the behaviour of prestressed concrete assemblies (2) subjected to loadings which simulate the effects of earthquakes induced in frameworks of which they may be components. This paper will attempt to forecast the effect the research appraisal and the Loadings Code( 3 ) may have on design and construction work where prestressed concrete frames not subject to the exemption permitted for buildings with low inelastic demand are chosen to provide resistance to earthquakes.

\section{CAPACITY DESIGN}

The Loadings Code formally introduces a design method, known as "the capacity method", the principal effect of which is to give the coup de grace to elastic strength appraisal procedures which have for so long dominated, but which have been under attack in recent times.

The capacity method establishes a heirarchy of failure, devised to ensure, as far as it is reasonably possible to do that, that any structure under attack of sufficient severity to overcome its elastic resistance forms, before collapsing, a "favourable" mechanism, one that will absorb and dissipate as much energy as possible. The heirarchy is

\section{Beam flexure \\ 1. (a) Beam shear \\ 2. Column flexure \\ 3. Column shear}

The intention is that every item is dependent upon a more or less realistic capacity assessment through each of the items with lower numbers. An immediate consequence is that overdesign at any step other than the last one results in wastefulness not only in that element but in all subsequently designed elements. Consistent conservatism is cubed, for example, in the design of columns for shear.

Design of beam column joints for strength, a matter largely ignored hitherto, has a most important place in the design programme; but does not, as yet (for reasons which will be discussed), fit into the failure heirarchy.

\section{ELASTIC ANALYSIS}

Frame analysis must still, of necessity, be elastic. In so far as it is obvious that the distribution of forces throughout a framed structure after the elastic capacity has been exhausted in many places will, in general, be significantly different from the distribution that would be forecast from an elastic appraisal, it might be thought that a considerable degree of approximation in analysing for elastic effects should be tolerable. However, the effect of the Code's provision controlling the accuracy of determination of vibration period is to require (perhaps inadvertently) high precision for tall buildings. It is also not feasible to satisfy the requirement for torsion in its current form without making a study in detail of the elastic behaviour of every structure as a space frame under static lateral loading.

\section{ANALYSIS FOR MEMBER FORCES}

(a) Flexure in Beams

For design forces, elastic analysis furnishes directly only sufficient information to design beams for flexure.

Plastic hinges were energy dissipation occurs must be permitted to form at or near each end of each beam span. Between the designated plastic hinges, the locations of which may be controlled by the designer, and between each hinge and the support face in cases where the designer chooses to hinge away from column faces the member is elastic.

\section{(b) Shear in Beams}

Four moment capacity assessments, two for each hinge, are required. The member design shear is that which results from the greater of the combinations of each of the capacity moment induced shears with the shear induced by an appropriate gravity loading. Each capacity moment induced shear is to be found by adding those capacity moments with the same vector sense for the two hinges and dividing by the length between hinges. Capacity moments used must be realistically assessed allowing for possible overstrength of all steel, prestressed and unstressed, that is present at each hinge, at whatever realisable compatible strain pattern produces the greatest moment capacity. The ratio of realistic capacity moment to reliable capacity will always exceed unity because the reliable capacity moment includes the effect of a reduction factor and is appraised with "safe" material strengths. A reasonable approximation to this ratio would seem to be about 1.4 for typical prestressed beams; but this must be checked for each design.

For those prestressed concrete members containing draped cables the curvature of which counters a significant part of gravity load, loading combinations specified

* Consulting Engineer, Wellington. 
in the code many not make adequate allowance for the effects of earthquake vertical acceleration. Special studies might be needed in some or all cases.

\section{(c) Moment in Columns}

Some difficulties have been encountered by those designers who have used capacity procedures to determine column design moments. Few of these difficulties have been resolved by the Recommendations published by this Institute (4). Moreover, these Recommendations may excite controversy by advocating the use of beam cracking moment as the "drive" for column moment rather than beam ultimate moment of resistance. In so far as a condition precedent to the design of columns requires beam ultimate moment to exceed cracking moment, it is apparent that the Recommendations suggest that something less than maximum drive be applied to the column. Unless the capacity reduction factor for strength assessment of columns, unspecified in the Recommendations, is a smaller fraction of the capacity reduction factor for beams than is the cracking moment of beams of their ultimate capacity moment, the columns may not be protected by beam hingeing. This matter will need the attention of designers.

When it is resolved, a more vexing problem remains - that of determining how the "drive" moment is to be divided between column spans meeting at a joint. The procedure advocated by early proponents of the capacity method that a multiple, somewhat greater than unity, of the total moment be equally divided between the two column spans is demonstrably wrong. It is the writer's firm belief that no amount of research investigation designed to establish a single acceptable multiplier will succeed. This problen is, at the time of writing, being investigated. Ferhaps a more promising way is to find a rational magnifier for the elastic analysis column moments. This can be done by establishing the "joint centre" beam moments which ccexist with hinge formation in the manner shown in Fig. 1. The magnifier is then the ratio of the absolute sum of beam joint centre moments to the absolute sum given by the lateral force analysis. This magnifier is to be applied to analysis moments reduced to the critical column design sections, which should be taken to be sections at the top and bottom levels of steel in the beams. There is no need to consider gravity load induced moments because their effect is automatically included by the magnifier.

\section{(d) Axial Load in Columns}

Concurrent two-terminal hingeing of all beams framing into a column from each direction, thus delivering to the column the maxima (upward and downward) of moment induced axial loadings is a pair of design conditions obtained from strict application of capacity procedures; but is improbable in multistorey frameworks. There is, as yet, no reliably justified reduction technique. In the absence of one, a tentative recommendation for medium rise buildings is to reduce the beam drive axial loading to ( $1-.03 n)$ times its computed value, $\mathrm{n}$ being the number of storeys above the column section under consideration. To the tensile axial load (negative) should be added 0.9 times the gravity dead load and to the compressive axial load should be added gravity dead load plus 1.3 times gravity live load the latter having been appropriately reduced when, as is always the case for lower stories, the total floor area tributary to the column exceeds $20 \mathrm{~m}^{2}$.

\section{(e) Shear in Columns}

Again in accordance with capacity procedures, column shear is to be found from column terminal moment capacity and again there are questions unresolved. column design will be controlled in most cases by the minimum axial 1oad; but increase in this load generally increases moment capacity and this must be considered.

Interim rules proposed by MWD officers for reinforced concrete frames require moment capacity at maximum axial load or the greatest capacity at axial load between minimum and maximum, if this is greater, to be used for shear calculation. Currently it is proposed that the capacity assessment (and hence the moment induced shear calculation) shall be made separately along each of the rectangular axes defined by framing beams. Designers will recognise that these capacities may greatly exceed the capacity of beams to develop moment in column terminii, and that column shear may be unduly conservatively assessed on that account. Partly in recognition of this fact and partly because the object of design is to eliminate column hingeing so that the probability of simultaneous hingeing in the same vector sense at each end of a column in a storey must be very low, it is suggested that column shear should be calculated at 1.5 times the greater of the two terminal capacities divided by the clear storey height.

\section{(f) Joint Shear}

Published procedures for estimating the furce to be resisted by shear steel are not altogether convincing. The problem of force determination and of design has complexities which are not immediately obvious, but which are troublesome in practice.

Clearly it is not possible to discuss these in detail in this paper. As an interim suggestion, the writer proposes that the shear be equated to the sum of design moments above and below the joint (in the same vector sense) divided by the distance between extreme layers of steel in the beam. This method of finding shear as a moment gradient has four advantages. First, it avoids the difficulty of which column shear should be subtractea from the force introduced by beam steel and beam concrete. It is because there are problems with column shear decrement that joint shear does not fit into the failure heirarchy. second, it is applicable when the designer chooses to keep beam hingeing away from the face of the column. Third, it encourages the designer to recognise that the selection of beams of deeper section than columns, which has been advocated (because that reduces the column shear) does nothing to reduce the beam moment gradient and that is, of course, joint shear. (Discerning designers will, by this time, recognise 
that the disposition of principal reinforcement, prestressed or unstressed, in the column may have a significant effect on joint shear behaviour, and that columns with main bars grouped in their corners are, perhaps, undesirable.) Finally, because the moment gradient method uses moments already calculated for column design, it is easier in practice than are other methods.

\section{MEMBER DESIGN}

Specific recommendations for design are given in Ref. (4). No doubt, as experience accumulates these will be modified and the daunting number of thoroughly arbitrary factors in both code and Recommendations will be reduced by substitution of more rational factors for some of them. It is, in the current state of knowledge, unfortunately necessary to be arbitrary. It will not have escaped readers that many more arbitrary decisions than have been made by those who devised the code and those who devised the Recommendations of the Seismic Committee of the NZPCI must be made by designers. It is urgently necessary to have authoritative guidance on at least some of these matters.

The business of element design cannot be explored in any depth in a paper of practical length, and even it if could be, any paper written now would have to be speculative, since no significant prestressed concrete building structure to the new Code and to the Recommendations has yet been constructed. For the meantime, designers should be guided by the code and the Recommendations.

\section{JOINTS AND LOCATION OF BEAM HINGES}

Because formidable bond problems can be seen to exist with a joint when beams hinge in the same vector sense at the faces of the column, and because tests have confirmed that there is indeed a risk that the bond on stressing tendons or on unstressed steel near the beam edges will fail to supply the necessary tendon or steel force gradient, Bertero and Popov (5) have advocated locating hinges away from the beam ends.

It is indeed advantageous to do this for more reasons than simply to relieve the bond, though that reason is compelling enough. Uncomplicated reinforcement can be devised to force the hinge to a location away from the face, though the reinforcement arrangement reported by Bertero and Popov and tested by their team would not please many contractors. In the arrangement shown in Fig. 2 all the steel distributed throughout the depth of the beam is as efficient in resisting moment as it would be were it located in two equal groups, each one half of this steel, one group at the top and the other at the bottom. The increment to capacity it provides is designed to be more than is required to prevent hingeing in the length it reinforces. The attraction is that this steel also confers on the joint, if properly designed, sufficient capacity to resist the joint shear. Moreover, since the joint is not flanked by severely distorted, cracked and crushed material, as it would otherwise be, the joint concrete is indeed confined, is elastic, and must be available, probably at an enhanced value, to assist in joint shear resistance:
Engineers in this country have regarded with justifiable scepticism the "confined joint" bonus offered by Appendix A of the ACI Code (6), doubting that when hingeing occurs at the column face there is much effective confinement of the joint concrete. Until tests have been done on the type of joint shown in Fig. 2 it will remain unwise to do anything so drastic as to halve joint shear as suggested by ACI. But it is entirely reasonable to accept a concrete contribution to shear when the hinge is away from the face, just as it is reasonable to count all steel except that in the outer layers of framing members as contributing to shear resistance.

Advantages are that smaller joints can be reinforced, hence member sizes can be smaller, awkward to place within-joint ties are either eliminated or substantially reduced and hinge areas can be made more ductile. Disadvantages are that a somewhat larger rotation capacity is required for the same displacement ductility factor (though in practice this is offset by hinge improvement) and that it may be impractical to use the scheme with the traditional sort of precast element construction. In this form of construction beams are assembled between framing columns with moist pack joints at column faces and the elements are connected by post tensioning cables. Special and somewhat awkward detailing would be needed to place the "through joint" distributed steel.

A joint of the type shown in Fig. 2 has been devised in the writer's office and given trial use in a seven storey reinforced concrete hospital building with MWD interest and approval. A test programme has been agreed and results will be reported in due course.

It appears that a near optimum shift of the hinge from the column face is about one beam depth, though this will vary a little with loading and geometry. Maximum efficiency is achieved if the steel required to ensure that the length between the column face and the hinge remains elastic matches that required for joint shear.

\section{CONCLUSION}

Prestressed concrete design engineers will be encouraged to have had demonstrated to them by the recognition given to the material as one suitable for earthquake resistant construction in the new code that at least some of the former pessimism about the material is dispelled. That this has happened in New Zealand whereas in, for example, California little progress has been made is certainly due to the fine research work that has been done at the University of Canterbury, consistently encouraged both technically and financially by the Institute, and to the responsible attitude recently adopted by the Institute's Seismic Committee.

There is much to be done yet to remove anomalies and to improve design procedures, both those of the code and those of the Recommendations, before consistent and reliable design can be done in all offices. If prestressed concrete is to retain the recognition this Institute has had to 
struggle so hard to achieve for it, the work must be continued. While important questions remain unresolved, it is imperative that designers use proper caution in exercising their judgement.

8. FEFERENCES

1. "The New Zealand Loadings Code and its application to the Design of Seismic Resistant Prestressed Concrete Structures", G. W. Butcher, NZPCI, 1976.

2. "Recent New Zealand Pesearch into the Behaviour of Prestressed Concrete Structures Subject to Seismic Loading", R. Park, NZPCI, 1976.

3. New Zealand Standard Code of Practice

for General Structural Design and Design Loadings for Buildings (NZS 4203:1976), Standards Association of New Zealand.

4. Recommendations for the design and Detailing of Ductile Prestressed Concrete Frames for Seismic Loading, The Seismic Committee of the NZPCI, Bulletin of the New Zealand National Society for Earthquake Engineering, Vol. 9, No. 2, June, 1976.

5. Hysteretic Behaviour of Ductile Moment-Resisting Reinforced Concrete Frame components", V. V. Bertero and E. P. Popov, Report No. EERC 75-16, 1975. University of California, Berkeley.

6. Building Code Requirements for Reinforced Concrete (ACI 318-71), American Concrete Institute.

FOOTNOTE: The author wishes to clarify two matters where there were inadequacies in his presentation to the Prestressed Concrete Institute.

The statement in the last paragraph of section $4 b$ concerning draped cabie balancing load applies with at least equal force to the flexure problem discussed in $4 a$ as to the shear problem of $4 b$

In section 4c, the author reads the PCI Recommendations as advocating a "cracking moment" beam drive. This may be an erroneous interpretation. Nevertheless, there is no clear statement in the Recommendation that overstrength beam drive must be used, so the error, if it is an error, will have a beneficial effect if it draws designers' attention to this fundamental of the capacity method. 


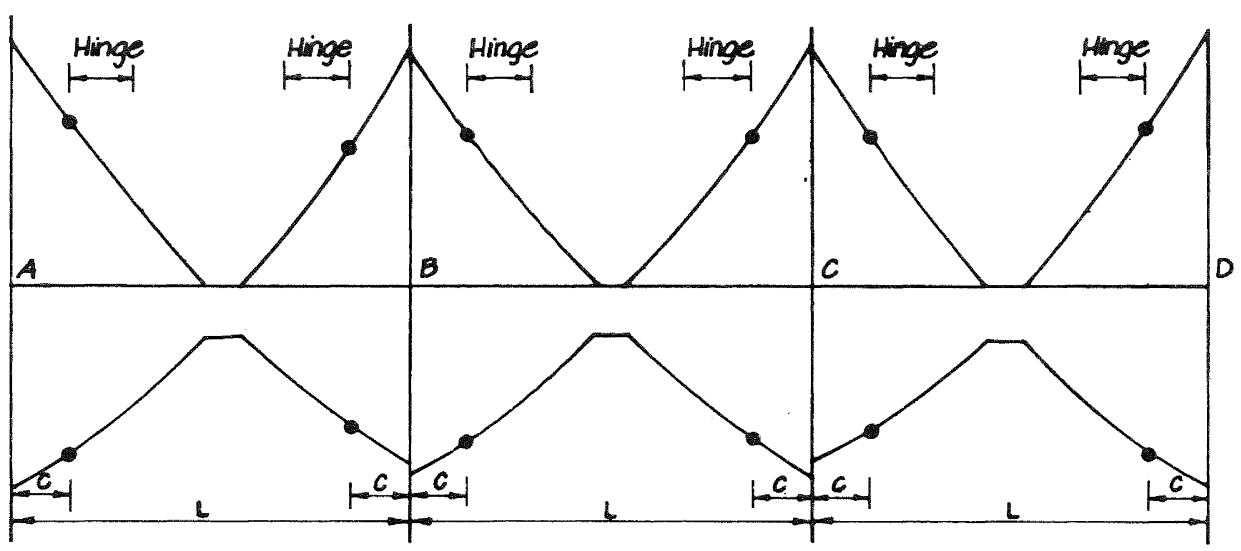

Beam moment emelope is used for flexund strength design. Reliable capocity matches demand as nearly as possible at paints indicated by dois. Elsewhere there is excess capacity.

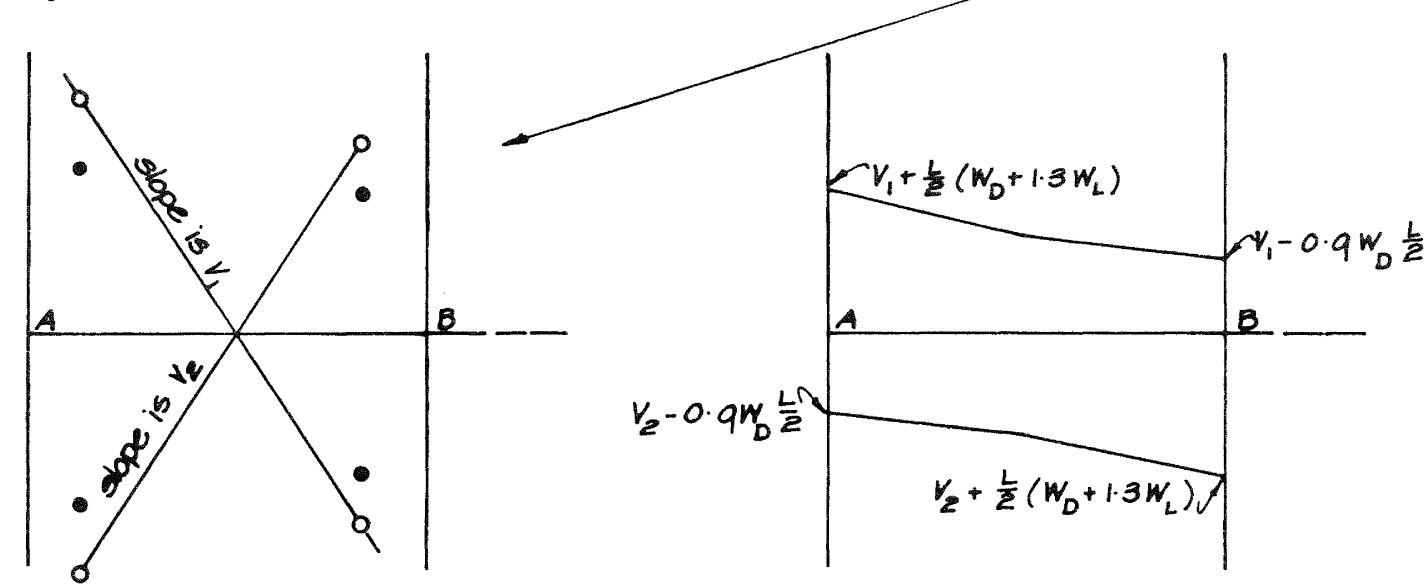

Reliable capacity is shown by dots. overstrength by open circles. Slopes of connecting lines are moment induced shear
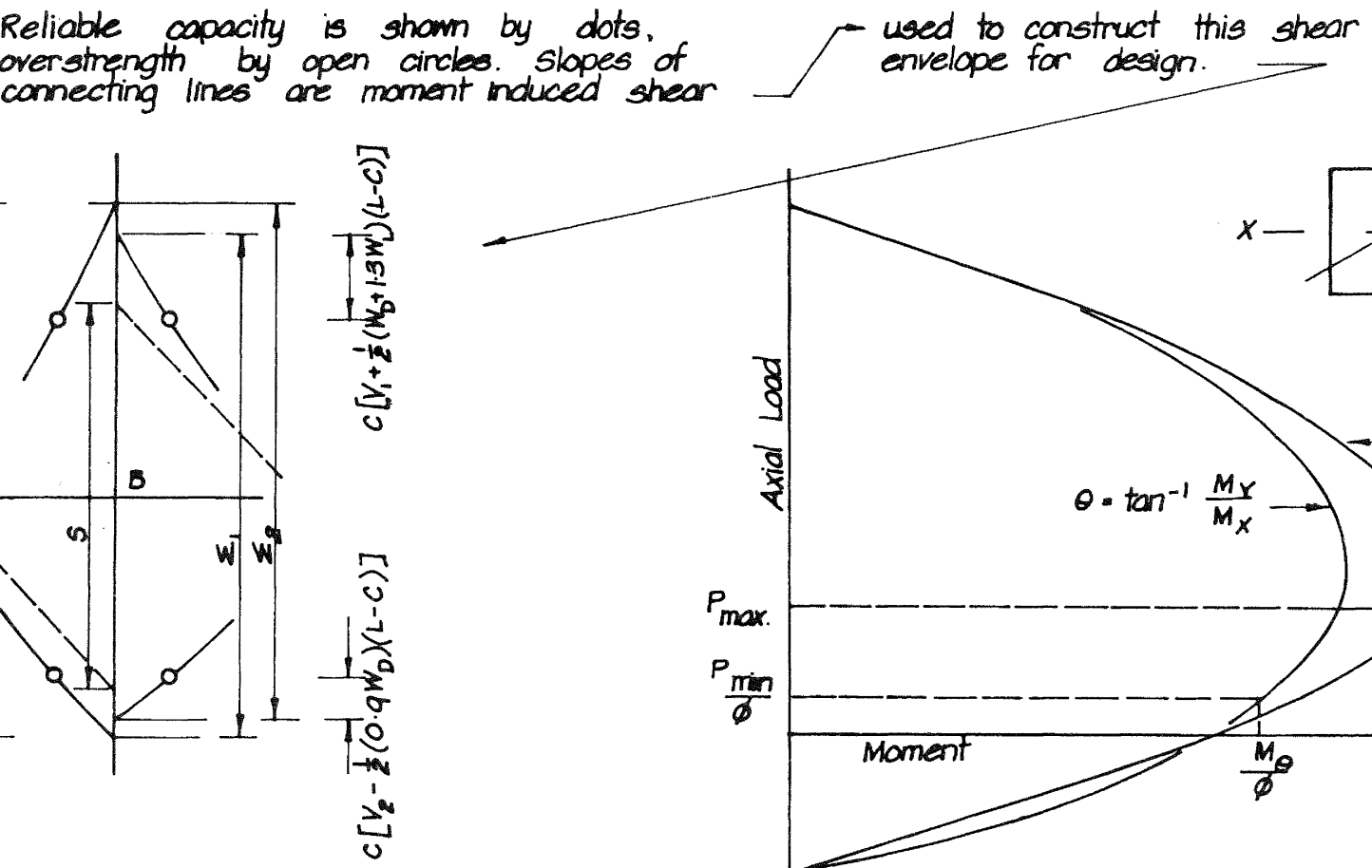

Beam moment differences establish the column moment magnifier. $\gamma$, to be applied to beterd fonce analyois col. moments at critical sections near this joint. Primed quantities refer to span AB. unprimed to $B C$. The broken line is lateral force analysis beom moment, open circles hinge overstrength copacities.

$\gamma=\frac{E}{3}$, where $\varepsilon$ is the greater of $\Sigma_{12} E_{2}$ Dasign columns for concurrent moment obout each axis.

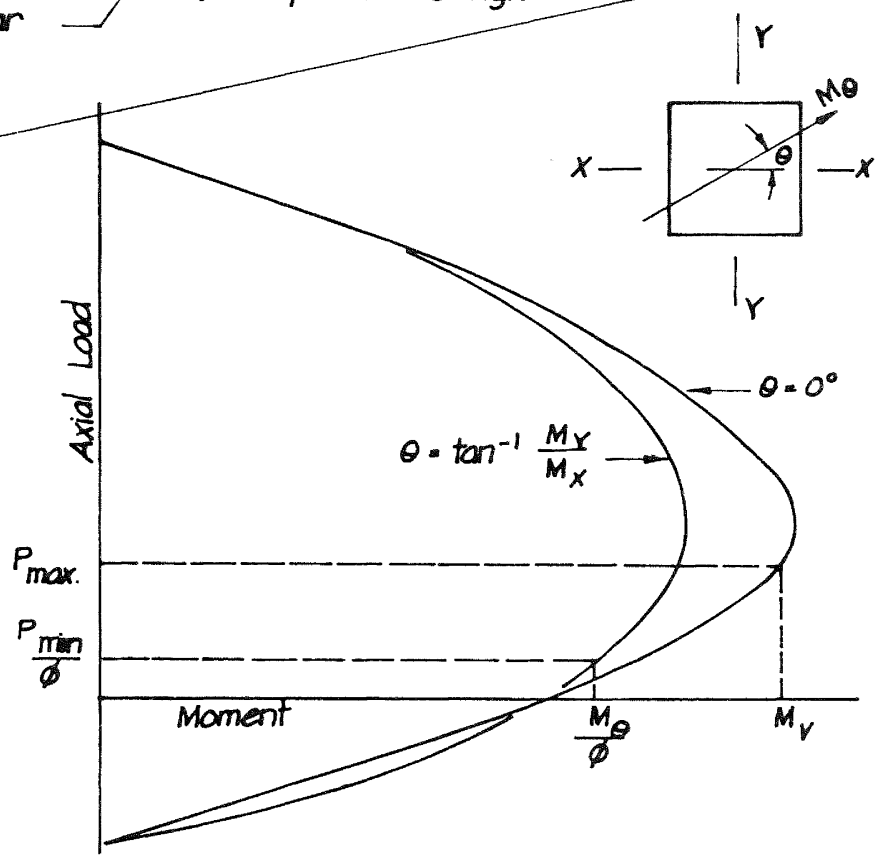

- Tentative recommendation for column shear design is shown on this $\phi-1$ interaction diagram. use $M_{v}$ to find moment induced shear. see text. 

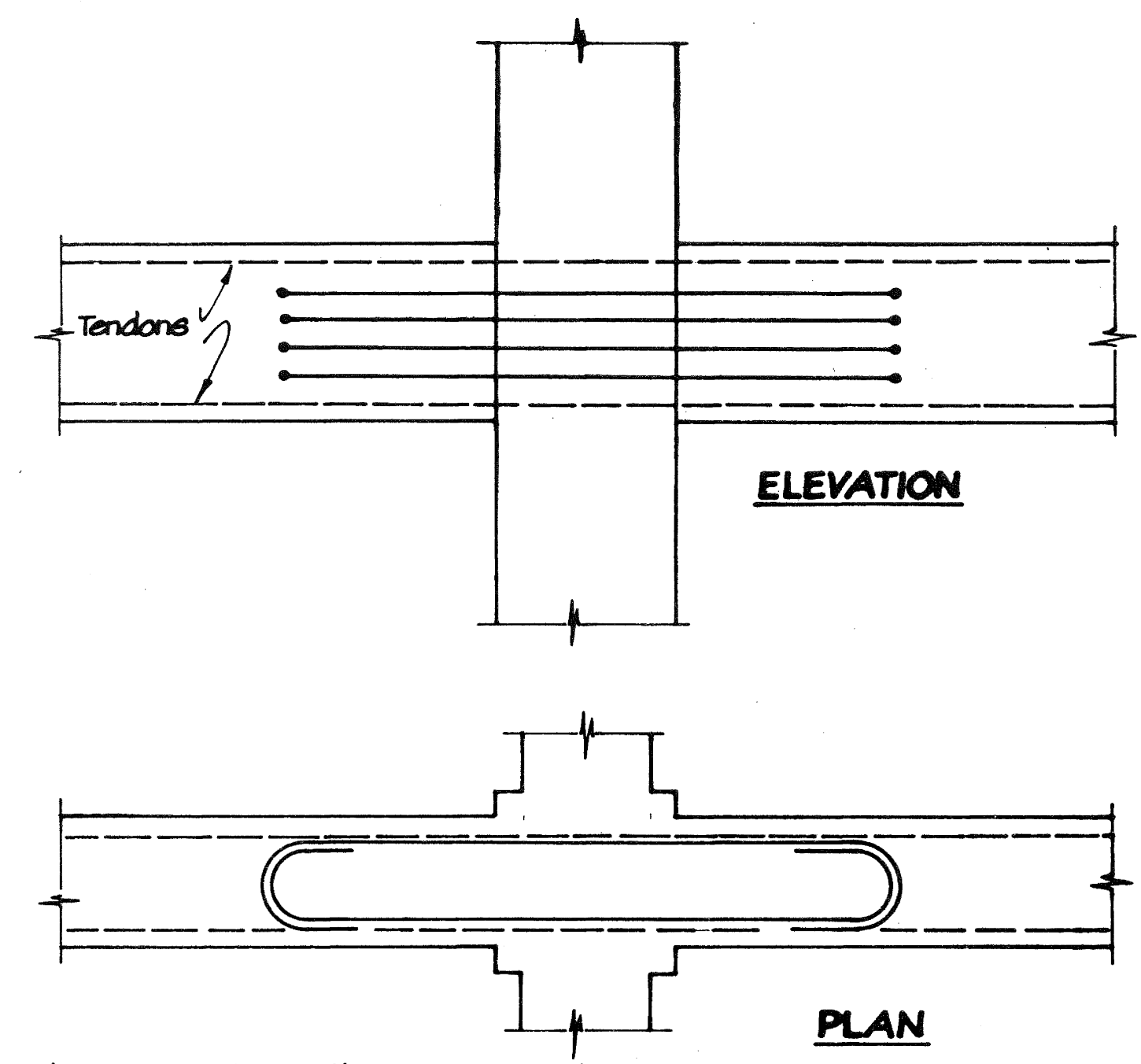

roint steel (unstressed) is designed -

(i) to control hinge location - suffictent for the beam capacity at the column face to be safely above the hinge overstrength capacity controlled moment there.

(ii) to reinforce the joint for shear due to the gradient between column design moments at the levels of top and bottom tendons.

FIGURE 2: BEAM-COLUMN JOINT 